\title{
Desafios atuais da área da comunicação
}

Profa. dra. Delia Crovi Druetta

Comunicóloga e latino-americanista. Professora e pesquisadora da Facultad de Ciencias Políticas y Sociales da Universidad Nacional Autónoma de México - UNAM. Pesquisadora nacional no Sistema Nacional de Investigadores do Consejo Nacional de Ciencia y Tecnología - CONACYT. Publicou diversos artigos e livros sobre temas de Comunicação e novas tecnologias. Atualmente é responsável pela pesquisa "Meios de Comunicação e construção social da incerteza", financiada pelo Programa de Apoio a Projetos de Pesquisa e Inovação Tecnológica da UNAM. É coordenadora do Programa de Pesquisa Social em Tecnologias da Informação do macroprojeto da UNAM, "Tecnologias para a Universidade da Informação e da Computação".

Quais são os problemas enfrentados atualmente pelos profissionais e acadêmicos da área da Comunicação na América Latina? Esta é a pergunta que tentamos responder, de modo muito geral, com estas reflexões. Partiremos da premissa de que tal campo vem se transformando de maneira significativa, desde os anos 1970, sob três eixos: as novas Tecnologias da Informação e da Comunicação - TIC; o modelo político-econômico neoliberal; e o paradigma da Sociedade da Informação e do Conhecimento - SIC. Com essas transformações, a Comunicação se redimensiona e passa a atuar em atividades impensáveis até então. Assim, as inovações tecnológicas determinam novas formas de produção, transmissão e recepção de mensagens, ao passo que as práticas culturais dos cidadãos e de seu meio social modificam-se, gerando novos modos de comunicar-se.

Distinguimos dois grandes universos de ocupação no campo da Comunicação: o profissional e o acadêmico. Neste texto, vamos nos referir especificamente ao segundo, ainda que muitos profissionais atuem nos dois universos. Esses âmbitos podem compartilhar os mesmos desafios, como a atualização permanente e a operação das TIC; ou podem ter desafios específicos como, por exemplo, os novos modos de produção para meios audiovisuais e impressos, ou a manipulação de um enorme volume de informação entre os pesquisadores.

Esse contexto permite-nos sustentar que, enquanto conjunto, o campo da Comunicação apresenta desafios de ordem endógena e exógena. Vamos nos referir brevemente a eles a fim de apontar alguns dos principais desafios atuais.

\section{A JUVENTUDE DA ÁREA E SUA FALTA DE IDENTIDADE COMO DESAFIOS ENDÓGENOS}

Existem desafios próprios da Comunicação e que repercutem na formação acadêmica e profissional, assim como no modo de entender essa formação. Talvez o maior deles seja a falta de identidade. Como sabemos, a identidade 
é relacional, isto é, constitui-se a partir do olhar dos demais. Nesse sentido, a Comunicação padece daquilo que Enrique Sánchez Ruiz e Raúl Fuentes Navarro denominaram anos atrás como a tríplice exclusão: da área das ciências sociais, da área das ciências em geral e do saber científico. Como resultado dessa falta de visibilidade científica, a Comunicação foi relegada dos pressupostos oficiais e do pensamento positivista.

A pouca idade da Comunicação, que começou a ser estudada na década de 1920, é outro fator que contribui para a frágil identidade da área. Por outro lado, os problemas da Comunicação sofrem uma espécie de migração, pela qual objetos próprios de seu campo de análise se deslocam para outras disciplinas no momento da pesquisa (por exemplo, as campanhas eleitorais passam para o campo da Ciência Política, os efeitos da mídia para o da Sociologia e as práticas de Comunicação para o terreno da Antropologia). Assim, dependendo de quem analisa, a área é objeto de avaliações e reconhecimentos diversos.

Se partirmos de sua juventude, o campo de conhecimento da Comunicação participa de algumas das características do processo de construção de identidade que os jovens experimentam. Carles Feixa indica que existem três elementos centrais que determinam as identidades juvenis: as culturas hegemônicas, nas quais engloba a escola, o trabalho, a religião etc.; as culturas parentais, ou seja, família, amigos e vizinhança; a biografia, com suas raízes, posicionamento e território. O período da vida denominado juventude caracteriza-se pela ruptura, por modos de expressão diferentes e, em muitos casos, pela rebeldia. Trata-se, em suma, de ir estabelecendo-se uma nova ordem de significações, através de um processo de autodeterminação.

Transpondo a mesma argumentação de Feixa para a identidade da juventude, veremos que, no âmbito da Comunicação, as culturas hegemônicas são representadas pelas práticas profissionais tradicionais, por um exercício tradicional do ensino, bem como pela própria concepção dos conteúdos dos planos de ensino. Os currículos dessa carreira na América Latina foram criados pelo Ciespal (Centro Internacional de Estudos Superiores de Comunicação para a América Latina), instituição que no final dos anos 1960 e no princípio dos anos 1970 estabeleceria as tendências na região. A partir de sua sede, no Equador, o Ciespal foi orientando a criação de carreiras com conteúdos amplos e de pouca especialização, bem como com uma acentuada preferência pela mídia impressa. Mesmo que isso se tenha transformado, a marca inicial perdura no modo de ser da carreira e configura um horizonte hegemônico no conteúdo de suas disciplinas.

Sociologia, Antropologia, Ciência Política, Psicologia, Economia e, em menor medida, Matemática e Engenharia são as disciplinas que configuram a cultura parental da Comunicação. Sua contribuição para o desenvolvimento do campo teórico e metodológico da Comunicação é fundamental e pode ser reconhecida em sua evolução histórica e nas perspectivas a partir das quais ela for analisada.

Finalmente, suas diversas raízes - o posicionamento ambíguo no âmbito científico e um território de ocupação bem pouco definido - têm impedido 
que a Comunicação conte com uma biografia sólida. Com base em culturas hegemônica e parental fortes, ficou difícil para a Comunicação alcançar sua autodeterminação, construindo uma biografia que delimite fontes, territórios e objetos de análise.

Carles Feixa utiliza uma excelente metáfora para explicar a situação dos jovens ante os adultos: a ampulheta ${ }^{1}$. Coloca na parte superior da ampulheta a cultura hegemônica, a cultura parental e as condições sociais que determinam a geração, o gênero, a classe, a etnia e o território. A fina areia, que lentamente vai escorrendo para a parte inferior da ampulheta, filtra-se naquilo que o autor identifica com o estilo (de ser, de se expressar). A passagem é feita através de duas técnicas: homologia e bricolagem. As imagens culturais que resultam dessa passagem para a parte inferior da ampulheta traduzem-se na linguagem, na estética, na música, nas produções culturais e nas atividades focais. Quando toda a areia tiver sido filtrada, a ampulheta torna a ser invertida e com isso se inicia um novo processo.

É possível aplicar essa metáfora à Comunicação? Se aceitarmos que a Comunicação é jovem e ainda passa por um processo de construção identitária, pode-se traçar um paralelo. Mas, nesse processo, a fina areia que lhe permitiria autodeterminar-se não está fluindo como deveria, e isso é que lhe impede de delimitar sua identidade, estabelecer-se como campo independente de conhecimento. Sem dúvida, não se trata somente de vontade própria, há também elementos externos que levam a Comunicação a propor-se, enquanto campo, ao menos três desafios:

a) É preciso delimitar suas próprias formas de ser e fazer, a fim de alcançar sua autodeterminação enquanto campo.

b)É preciso relacionar-se e conviver em condições de igualdade com disciplinas afins e com aquelas das quais surgiu e se alimenta.

c) É preciso escrever e contar sua própria história, construindo assim uma biografia que permita à Comunicação identificar-se e narrar-se enquanto campo de conhecimento. Como os jovens, torna-se necessário ir estabelecendo uma nova ordem de significações.

\section{DESAFIOS EXÓGENOS: NOVAS TECNOLOGIAS, NOVO MODELO POLÍTICO-ECONÔMICO}

Vale a pena recordar brevemente os antecedentes do momento que vivemos. Tanto o surgimento das TIC como do paradigma da SIC afetaram de maneira determinante a Comunicação, reposicionando-a e confrontando-a socialmente. Mas isso significou, ao mesmo tempo, o surgimento de desafios difíceis de enfrentar para uma disciplina jovem, com uma identidade frágil.

Para a América Latina, a década de 1980 foi particularmente importante porque nesse período iniciaram-se as políticas neoliberais e, com elas, as reformas do Estado. Nesse panorama destacam-se duas instituições: o Fundo Monetário Internacional - FMI - e o Banco Mundial - BM, que alcançaram o papel de
1. FEIXA, Carles. El reloj de arena: culturas juveniles en México (A ampuIheta: culturas jovens no México). México: Causa Joven, Centro de Investigación y Estudios sobre la juventud, 1998. (Colección Jóvenes, n. 4.). 
2. HAYEK, Friedrich. The use of knowledge in society (O uso do conhecimento em sociedade). American Economic Review, 35:4, September, $1945,519-30$

3. MONTUSCHI, Luisa. Datos, información y conocimiento, de la sociedad de la información a la sociedad del conocimiento (Dados, informação e conhecimento, da sociedade da informação à sociedade do conhecimento), 2006. Disponível em: <http://www.cema. edu.arg/publicaciones $>$.

4. DRUCKER, Peter Apud MICHELI THIRIÓN, Jordi. Digitofactura: flexibilización, internet y trabajadores del conocimiento (Digitofatura: flexibilização, internet e trabalhadores do conhecimento). Revista Comercio Exterior, México, v. 52, n. 6, p. 522-536, 2002 protagonistas diante da crise latino-americana que eclodiu nessa década pelo pagamento da dívida externa. Como sabemos, ante a ameaça que a crise representava para os Estados Unidos e seu sistema financeiro, surgem os pacotes de ajuste, segundo os quais é a população que assume os maiores custos. Nesse contexto, vai surgindo um novo tipo de sociedade e, também, um Estado com novas características: passa-se de um Estado de bem-estar, preocupado com a proteção dos empregos, a indústria nacional e o mercado interno, para um Estado Mínimo, o qual passa a ceder ao mercado suas responsabilidades como regulador da ordem social.

O FMI havia sido criado para corrigir a curto prazo os desequilíbrios monetários, mas não tinha capacidade para resolver problemas a longo prazo, como a já mencionada passagem de um Estado de bem-estar a um Estado mínimo. Então, surge o Banco Mundial como instituição encarregada de consolidar as reformas estruturais do Estado.

Foi em 1989, quando o economista John Williamson elaborou, baseado nesse contexto, o documento que logo ficou conhecido como Consenso de Washington, que iniciou uma mudança de rumo na economia mundial. A partir de então, as principais instituições econômicas internacionais estabeleceram, pela primeira vez, uma série de medidas que os países da América Latina deveriam aplicar. Essas medidas, supostamente, foram pensadas para garantir o crescimento econômico e o desenvolvimento da região, mediante diretrizes que orientavam a transição dos países para uma economia de mercado com inserção mundial.

Esse documento é considerado o ponto de partida da sociedade da informação e do conhecimento. Entretanto, trabalhos anteriores já haviam associado conhecimento e produção de riqueza. Com efeito, em 1945, Friedrich Hayek (posteriormente Prêmio Nobel de Economia) publicou um artigo intitulado The use of knowledge in society ${ }^{2}$, no qual argumenta que o sistema econômico mais eficiente era aquele que fazia uso pleno do conhecimento existente ${ }^{3}$. Em 1975, o conceito é empregado no contexto da Organização para a Cooperação e o Desenvolvimento Econômico - OCDE, inspirado na capacidade de armazenamento e transmissão da informação pelos processos de digitalização. Peter Drucker retomaria essas idéias no início dos anos 1990, afirmando que é possível aplicar conhecimento ao conhecimento com o propósito de chegar a um conhecimento superior ${ }^{4}$. Passados dezessete anos, podemos afirmar que a realidade nos diz algo bem diferente sobre o novo tipo de governo mundial proposto pelo Consenso de Washington. Longe de haver posto fim às diferenças digitais de conhecimento entre os países desenvolvidos e os mais pobres, foi origem de profundas crises nos países latino-americanos.

Do nosso ponto de vista, a liderança do FMI e do Banco Mundial tem uma importância crucial pelo fato de que essas instituições são as que se encarregam de aportar o conteúdo simbólico e a explicação das transformações que estavam acontecendo. $\mathrm{O}$ trabalho que desempenharam, além das orientações de caráter econômico por si só fundamentais, localiza-se no plano discursivo e simbólico, 
o que lhes permite ressignificar alguns conceitos e preencher de sentido outros que até então não existiam. Sua própria argumentação se transforma no modo de ser dos Estados e chega a ser conceito condicionante das políticas públicas e das ações governamentais.

Nessa realidade, a Comunicação intervém de maneira fundamental no novo modelo de sociedade proposto no fim do século passado. Por um lado, tanto informação como conhecimento têm uma dimensão social graças ao fato de que são compartilhados e comunicados, o que levou a Comunicação a reposicionar-se no mundo atual. Para alguns autores, esse reposicionamento permite à Comunicação integrar-se aos processos produtivos e constitui um fator de riqueza, abrindo numerosos desafios para a área. Por outro lado, no processo de construção simbólica do novo modelo social, os meios de Comunicação têm papel fundamental. Mas para que essa missão se cumprisse de acordo com as mudanças propostas, foi necessário reconfigurar o setor, começando por sua economia política e chegando até o tipo de comunicadores e comunicólogos que deveriam ser formados.

Dentre as ações levadas a cabo para mudar esse universo, destaca-se o processo de privatização dos meios públicos, que passam a mãos de operadores privados, alimentando a concentração desses recursos entre poucas empresas. Destaca-se também uma re-regulamentação, segundo a qual o dispositivo legal responde às exigências das privatizações, bem como à convergência tecnológica e de capitais. Esse novo marco jurídico permitiu ainda uma flexibilização trabalhista motivada pelo uso dos recursos digitais. No conjunto, as mudanças criam novas formas de produzir mensagens e novas aplicações dos processos de Comunicação, que exigem um tipo de profissional afinado com tais necessidades.

Especificamente no campo acadêmico, ganha força a educação a distância e, em geral, o ensino mediado pelas TIC. Ao mesmo tempo, longe de fortalecerse uma tendência à especialização do comunicador ou do jornalista, as escolas voltam-se para um trabalhador de banda larga ou pau para toda obra, que pode tanto trabalhar na imprensa como nos meios audiovisuais ou digitais.

Além disso, os processos de privatização chegam ao setor da educação, produzindo uma explosão de instituições de ensino superior, que podem ser agrupadas em universidades humanísticas (entre as quais a educação religiosa), universidades de negócios (a educação entendida como oportunidade de negócio), ou universidades coorporativas (educação instrumental a serviço da corporação, que a planeja, organiza e oferece). Nesse contexto, produz-se um enfraquecimento das posições tradicionais que tinham as universidades públicas, cujas funções vão muito além da docência para ocupar-se também da pesquisa e da difusão do conhecimento e das artes. A produção de quadros científicos, tecnológicos e artísticos para a reprodução do sistema se privatiza ao privatizarem-se o ensino e a produção do conhecimento.

Não se trata, desde já, de uma privatização grosseira que pretenda desembocar na compra das universidades públicas pelo capital privado, como se elas fossem um capital rentável; trata-se sim de uma privatização sutil que vai criando todos 
5. VILLASEÑOR, Apud COMBONI, Sonia; JUÁREZ, José Manuel; PARÍS POMBO, María Dolores. Hacia dónde va la Universidad Pública? La educación superior en el siglo XXI (Para onde vai a universidade pública? $A$ educação superior no século XXI). Universidad Autónoma Metropolitana, Unidad Xochimilco, México, 2002. p. 61.

6. DELORS, Jacques (Coord.). La educación encierra un tesoro. Informe a la UNESCO de la Comisión Internacional sobre la Educación para el siglo $X X I$. (A educação encerra um tesouro. Relatório da Comissão Internaciona sobre a Educação para o século $\mathrm{XXI}$, apresentado à UNESCO). Correo de la UNESCO, México, Ed. Unesco, 1996

7. UNESCO. Organización de las Naciones Unidas para la Educación, la Ciencia y la Cultura. Conferencia Mundial sobre Educación superior. Declaración Mundial sobre la Educación Superior en el Siglo XXI: Visión y Acción (A educação superior no século XXI: Visão e ação). ED-98CONF.202/3, París, 9 octubre 1998.

8. BANCO Mundial. El conocimiento al servicio del desarrollo. Informe sobre el desarrollo mundial (O conhecimento a serviço do desenvolvimento. Informe sobre o desenvolvimento mundial). Washington, 1999. Disponível em: <http://www. bancomundial.org>.

9. PINEDA, Migdalia. Antonio Pasquali: el maestro y su utopía (Antonio Pasquali: o mestre e sua utopia. Entrevista). Revista Latinoamericana de Investigación de la Comunicación. Brasil, Asociación Latinoamericana de Investigadores de la $\mathrm{Co}$ municación - ALAIC, ano II, n. 2, p. 86-94, jan./jun. 2005

10. <http://www.anuies.mx> os mecanismos possíveis para que os três produtos das universidades públicas (formandos, conhecimentos e valores) sejam canalizados de acordo com as necessidades competitivas diferenciadas do capital privado ${ }^{5}$.

As transformações na educação superior foram devidamente orientadas pela Unesco, primeiro através do Relatório Delors ${ }^{6}$, A educação encerra um tesouro, e dois anos depois pela Conferência Mundial sobre educação superior ${ }^{7}$. Ambos os documentos refletiriam em ações concretas levadas a cabo pelos países latino-americanos.

Enquanto os documentos da Unesco enfatizam o ensino, um relatório de 1999 produzido pelo Banco Mundial, e denominado $O$ conhecimento a serviço do desenvolvimento $^{8}$, vai além, identificando também pesquisa e divulgação. Argumenta que se a maior parte da população do mundo tivesse acesso à informação, não só se reduziriam as diferenças em matéria de conhecimento, mas até mesmo seria um fator decisivo para elevar o crescimento econômico e a qualidade de vida nos países de menor desenvolvimento. De acordo com esse organismo, três passos permitiriam cobrir tal tipo de necessidades: a aquisição de conhecimentos, sua absorção e a Comunicação desses conhecimentos. A aquisição de conhecimentos está ligada à pesquisa científica, a absorção de conhecimentos está associada aos processos educativos e a Comunicação de conhecimentos refere-se ao uso otimizado das TIC nos processos de difusão.

Essas transformações, relacionadas ao surgimento de novas mídias e recursos (internet, telefonia celular, rádio e TV digital, entre outros), implicam a recolocação teórica e metodológica da área. Impõe-se a atualização dos professores através de uma profunda formação nos novos parâmetros impostos pelas tecnologias, mas, acima de tudo, pelo novo modelo político-econômico neoliberal. Em matéria de pesquisa, os temas emergentes são vastos e é impossível atender a todos, já que o grupo de acadêmicos dedicados a analisá-los é pequeno.

Apesar de ter-se produzido um crescimento desmedido no número de escolas de Comunicação, elas não são adequadas para responder aos problemas emergentes. Isso se deve a suas diversas origens, propósitos e qualidade. Segundo Antonio Pasquali ${ }^{9}$, a América Latina conta com cerca de mil escolas e faculdades de Comunicação, das quais cerca de 600 localizam-se no Brasil e no México. Essas escolas atendem a uma população estudantil de cerca de 400 mil alunos. A Associação Nacional de Universidades e Instituições de Educação Superior - Anuies, do México, reconhece a existência de 315 programas de Comunicação em todo o país. Setenta por cento desses programas responde às denominações dadas pela Ciespal no final dos anos 1960: Jornalismo, Jornalismo e Comunicação, Ciências e Técnicas da Informação, Ciências da Comunicação e Comunicação ${ }^{10}$.

Parece que, em matéria de formação de comunicadores e comunicólogos, muitas escolas estão olhando para o passado em vez de olhar para o presente ou para o futuro. $\mathrm{E}$ isso se deve ao fato de que a área é percebida como um nicho a ser explorado dentro do mercado da educação e, portanto, no lugar de se investir para criar novos conteúdos de acordo com os tempos atuais, copiam-se os existentes em programas tradicionais, mas que não se atualizaram suficien- 
temente. Assim, apesar de ser necessária uma depuração da oferta, é também indispensável a adequação dos programas tradicionais às necessidades de hoje.

\section{RUMO À FORMAÇÃO DE UM NOVO PROFISSIONAL}

Em matéria de formação de um novo tipo de profissional de Comunicação, as universidades têm diante de si o enorme desafio de capacitar os trabalhadores da era digital. No cerne da modificação que atravessa a organização sociotécnica do trabalho, os profissionais hoje em dia são co-responsáveis pelo funcionamento dos processos produtivos ou serviços. Devem ser formados para trabalhar em equipe, para se adaptar às condições de mudança e para identificar e resolver problemas. Capacidade de abstração, raciocínio e habilidade para tomar decisões em tempo real são algumas das características necessárias na nova concepção dos processos de trabalho.

Por outro lado, no exercício do jornalismo, a evolução tecnológica tem reunido em um só sujeito atividades que antes eram realizadas por vários: fotografar, entrevistar, coletar informação e processá-la. O enorme volume de informação disponível na internet representa uma mudança substancial na forma de elaborar os textos.

De modo geral, estamos diante de uma nova cultura do trabalho que inclui um reduzido número de trabalhadores altamente qualificados, preparados em sua maioria pelas universidades. Alguns desses profissionais são analistas simbólicos, entre os quais se destacam aqueles que manejam profissionalmente a informação. Esses trabalhadores estão sujeitos também a duas demandas: no interior de seu espaço de trabalho existe uma nova divisão técnica das funções ligada à formação sistemática e a um processo de atualização permanente; e fora do mercado de trabalho, há um universo restritivo, altamente competitivo, em que até mesmo as TIC podem intervir negativamente, ao eliminar postos de trabalho que foram substituídos por processos automatizados.

[...] grande parte do capital intangível constitui-se de investimentos em capacitação, instrução, atividades de pesquisa e desenvolvimento, informação e coordenação, ou seja, por investimentos consagrados à produção e à transmissão do conhecimento $^{11}$.

Esses investimentos respondem à diferença substancial que existe entre informação e conhecimento. Apesar de muitas vezes ambos serem equiparados, há divergências: a informação é apenas um conjunto de dados que não se atualizam até que sejam empregados por quem esteja em condições de interpretá-los, de dar-lhes uma forma e de comunicá-los socialmente. O conhecimento, por outro lado, nos remete à capacidade de realizar atividades de ordem intelectual ou manual e, portanto, é fundamentalmente uma capacidade cognitiva ${ }^{12}$. Sua reprodução e conservação respondem a um modelo educativo que, como vimos, está mudando, assim como os novos instrumentos técnicos para armazená-lo e fazê-lo circular. Além disso, estão se modificando as formas tradicionais de transmissão do conhecimento do professor ao aluno, e há inclusive uma alte-
11. DAVID, Paul A.; FORAY Dominique. Una introducción a la economía y a la sociedad del saber (Uma introdução à economia e à comunidade do saber). 2002. Disponível em: <http://www.campus-oei. org/salactsi/david.pdf>.

12. Ibid. 
ração na relação entre as gerações, já que muitos jovens conhecem mais sobre as TIC do que os professores e os mais velhos.

Se as instituições de educação superior não superarem esses desafios impostos pelas mudanças tecnológicas e pelo modelo neoliberal, a perda de saber pode ser iminente. Por isso e nesse contexto, é razoável que nos perguntemos se as universidades estão fazendo o suficiente para produzir uma transformação de magnitude similar em seus professores, pesquisadores e divulgadores de conhecimento. As TIC já não são uma revolução tecnológica; são inovações que se inscrevem em um novo modelo de sociedade para o qual as universidades devem formar seus egressos, mas antes precisam formar também seus próprios docentes, pesquisadores e divulgadores.

\section{A PESQUISA}

A pesquisa em Comunicação esteve sempre dividida em dois grandes universos:

a) A instrumental ou aplicada.

b) A acadêmica ou científica.

Em matéria de pesquisa instrumental ou aplicada, a Comunicação conta com dois segmentos visíveis: a publicitária, em todas as suas variantes, e a administrativa, realizada por encomenda. O conhecimento que se produz nessas áreas é muito importante. Entretanto, fica encerrado nos limites do mercado, que impede sua divulgação.

Quanto à pesquisa acadêmica ou científica, a partir dos processos de privatização, está sujeita a orçamentos públicos exíguos, bem como às tendências que marcam os financiamentos nacionais e internacionais. As mudanças experimentadas pelos setores produtivos, a concentração econômica, a re-regulamentação marcam de fato uma agenda de pesquisas que vai deixando de lado outros temas igualmente importantes, diante da impossibilidade de englobar a todos com tão poucos recursos para análise ou pela falta de apoio para realizá-la.

Assim, no panorama atual, a formação de quadros para a pesquisa da área ficou nas mãos das universidades públicas e de algumas poucas de caráter humanístico. O pensamento crítico, a auto-reflexão e a pesquisa, instrumentos essenciais para fortalecer a identidade da Comunicação, se perdem diante da abundância de programas cujo fim é a operação de equipamentos midiáticos, mas não de seus conteúdos. Isso não quer dizer que não existam instituições de educação superior com uma missão clara: a formação de pessoal para trabalhar na mídia de acordo com o sistema vigente, isto é, pessoal apto para sustentar sua reprodução simbólica.

O sinal vermelho que se acendeu nos últimos anos diante das propostas de transformação na educação superior não deve nos levar a pensar que as universidades públicas não necessitem modificar-se. Pelo contrário, enfrentar os desafios do presente implica começar por essas mudanças. Além disso, nem todas essas transformações foram negativas. Destaque-se, por exemplo, o forte 
impulso à pesquisa acadêmica dado através das pós-graduações em Comunicação, que se iniciaram na América Latina no final dos anos 1970 e começo dos 1980. Desde então, a pesquisa, dispersa e não legitimada, começa com um processo ascendente de institucionalização. Os sistemas de avaliação, a força que adquire o trabalho do orientador, o controle da eficiência na conclusão e os programas de bolsa são fatores que contribuem para tal institucionalização.

As teses, enquanto trabalhos acadêmicos, alcançaram rigor e cuidado teóricometodológicos, enriquecendo os estudos empíricos escassos em anos anteriores ao desenvolvimento dos programas de pós-graduação. A tradição anterior baseava-se no ensaio e manifestava um aberto entrecruzamento entre o exercício jornalístico e a pesquisa. Atualmente esses campos estão separados e a investigação empírica faz parte da história ainda não escrita do campo da Comunicação no México. Algo parecido tem ocorrido em outros países da região.

Apesar do critério da eficiência, medido numericamente, sob o qual se orientam na atualidade os processos de avaliação e controle da educação superior, pode-se atribuir a eles um impulso à pesquisa que, entretanto, é efêmero. Numerosos estudantes de pós-graduação, ao defender suas teses, buscam a inserção no campo acadêmico, mas as restrições em matéria de vagas os levam a optar por outros caminhos em sua vida profissional. Nesse contexto, os quadros docentes e de pesquisadores padecem de pouca renovação, o que paulatinamente levará a um empobrecimento da área em termos teóricos e metodológicos.

\section{CONCLUSÃO}

Em matéria de construção da área de conhecimento da Comunicação, assim como da formação de seus profissionais, a América Latina tem seguido os mesmos passos e enfrentado desafios semelhantes. Desde a semente plantada pela Ciespal no final dos anos 1960, passando pela tríplice exclusão da qual a Comunicação tem sido historicamente objeto, até chegar a um redimensionamento ideológico e tecnológico como o atual, esse caminho vem sendo atravessado pelos poderes corporativos que os meios de Comunicação têm construído através da integração de monopólios e oligopólios. Também têm sido atores fundamentais os grupos no poder aliados a esses poderes corporativos.

Se a falta de identidade da área constitui, em grande medida, um problema endógeno, o reconhecimento dos demais, o olhar em condições de igualdade de outras disciplinas e de outras áreas do saber, é um desafio exógeno. Ao faltar validade científica à Comunicação, subestimam-se os argumentos de sua importância social, seu peso político e econômico. Alcançar a autodeterminação implica necessariamente o reconhecimento exterior. Consideramos que escrever a história da área, construí-la histórica e socialmente, é uma tarefa que pode contribuir para enfrentar os desafios que se apresentam na alvorada do século XXI.

Assim e para além da disputa pelo estatuto científico da Comunicação, no México e na América Latina, a emergência de problemas nos quais esta 
área está envolvida exige uma atenção adequada e imediata. A influência da Comunicação e das mediações simbólicas, com uso de tecnologias ou não, cresce e é incontornável. Nesse contexto, os desafios endógenos e exógenos da Comunicação se potencializam entre si, integrando-se em um discurso único que deve lutar por alcançar um lugar na agenda das Ciências Sociais e da Ciência em seu conjunto. Com a Comunicação, o problema da cultura está em jogo. Também está em jogo o desafio da difusão do conhecimento. E enquanto pensarmos que seu universo se reduz e se delineia na informação disponível ou nas mensagens das mídias, estaremos deixando de lado a importância central que tem a construção simbólica do mundo em que vivemos.

Resumo: Este artigo propõe reflexões sobre os problemas enfrentados atualmente por profissionais e acadêmicos da área da Comunicação na América Latina. Parte da premissa de que esse campo vem se transformando de maneira significativa, a partir dos anos 1970, sob três eixos: as novas Tecnologias da Informação e da Comunicação - TIC; o modelo político-econômico neoliberal; o paradigma da Sociedade da Informação e do Conhecimento - SIC. Distingue dois grandes universos de ocupações no campo da Comunicação: o profissional e o acadêmico. Neste texto, vamos nos referir especificamente ao segundo, mesmo sabendo que muitos profissionais atuam nos dois universos. Esses âmbitos podem compartilhar desafios semelhantes ou específicos. Tal contexto permite-nos sustentar que, enquanto conjunto, o campo da Comunicação apresenta desafios de ordem endógena e exógena.

Palavras-chave: Ciespal, formação profissional, TIC, neoliberalismo, SIC.
Abstract: This article proposes reflections on the problems faced nowadays by Latin American academic and non-academic professionals of the Communication area. It assumes that this field is being transformed in a significant way since the 70's under three axes: the new Information and Communication Technologies - ICTs; the neo liberal political and economic model; and the paradigm of the Information and Knowledge Society - IKS. It distinguishes two universes of occupation in the Communication field: the academic and the non-academic. This work refers specifically to the first one, even recognizing that many professionals act in both universes. They can share the same challenges or have specific ones. This context allows us to affirm that, as a set, the Communication field presents challenges of endogenous and exogenous nature.

Keywords: Ciespal, professional formation, ICT, neo liberalism, IKS 